\begin{tabular}{lllll}
\hline Motrivivência & Ano XX, & No 31, P. 346-353 & Dez./2008 \\
\hline
\end{tabular}

\title{
Está Chovendo, e Agora? A Educação Física e o dia de chuva - um estudo de caso
}

\author{
Heloisa dos Santos Simon' \\ Andréia Rodrigues de Souza Cardoso² \\ Soraụa Corrêa Domingues ${ }^{3}$
}

\begin{abstract}
Resumo Abstract
No cenário de chuvas em 2008 In the scenario of rainfall in 2008 a turma de Educação Física da UFSC fez seu Estágio. O objetivo é entender como o dia de chuva se torna um desafio nas aulas práticas. Fizemos entrevistas com docentes universitários e colegas de estágio. Nas respostas percebemos que o dia de chuva não é problema para todos, mas mudanças são necessárias para adequar as aulas; pois os espaços escolares limitam a Educação Física nessa condição. Superar o (problema) dia de chuva depende de melhoria na infra-estrutura e professores com disposição para elaborar estratégias para a chuva passar de empecilho a possibilidade de conteúdo.

Physical Education students of UFSC did its internship. The goal is to understand how the rainy day becomes a challenge in practical classes. We conducted interviews with academics teachers and internship colleagues. In the answers we realize that the days of rain is not a problem for everyone, but changes are necessary to adapt the lessons; that school spaces narrow physical education in this condition. Overcoming the (problem) rainy day depends on improvement in infrastructure and teachers in the mood to elaborate strategies for the rain move from roadblock to possibility of contents.
\end{abstract}

Palavras chave: Educação Física; Escola; Dia de chuva.

Key words: Physical Education, School, Rainy Day.

\footnotetext{
Estudante de Educação Física/UFSC. Contato: heloisa_simon@hotmail.com

Estudante de Educação Física/UFSC

3 Doutoranda no PPGEF/UFSC, possui graduação em Educação Física mestrado em Educação pela UFBA.
} 


\section{Introdução}

Visualize a cena: Você é um professor de Educação Física $(\mathrm{EF})$, e prepara suas aulas rotineiramente de acordo com suas possibilidades materiais, físicas, hábeis e público-alvo. Você prepara a sua aula pensando no campo de areia, ou utilizando o espaço da quadra esportiva, então quando acorda pela manhã, percebe que está chovendo. O que fazer agora? E a aula planejada para o espaço aberto? Adaptar para algum espaço coberto? Improvisar com atividades na sala de aula? Tais questionamentos surgiram quando alunas do Curso de Educação Física, no seu primeiro contato com a prática pedagógica do Estágio, enfrentaram um prolongado período de chuvas. Diante de tal desafio, buscou-se na literatura algo que referenciasse ou dissertasse sobre tais dificuldades ambientais, porém nada foi encontrado.

O estágio supervisionado em Educação Física no segundo semestre de 2008 ocorreu em uma escola Estadual inaugurada em 1940, a qual inicialmente atendia alunos da $1^{\mathrm{a}}$ a $4^{\mathrm{a}}$ séries com capacidade para 600 alunos. Com o passar dos anos as exigências escolares aumentaram, passando a atender alunos de $5^{\mathrm{a}}$ a 8 a séries e em 1980 após a construção de um prédio em anexo a escola passa a atender também alunos do Ensino Médio. Uma das instalações mais importantes para a Educação Física, o ginásio, foi inaugurado em 2005 e representa uma antiga e merecida reivindicação da comunidade, de um espaço adequado para prática esportiva com mais qualidade, antes a escola contava apenas com 4 quadras não cobertas que ainda são utilizadas. Os espaços da escola para a prática das aulas de Educação Física são divididos em cinco quadras ao ar livre e o ginásio coberto para as turmas acima da quinta série, que começam a ter aulas de iniciação desportiva. As turmas de pré e de primeira a quarta usam os demais espaços da escola, como o pátio, o parquinho e um campo de areia que era chamado de areão. Enfim, todas as áreas ao ar livre.

Durante o período de estágio enfrentamos um grande desafio. O segundo semestre de 2008 foi marcado pelas chuvas no estado de Santa Catarina, que devido à sua continuidade ocasionou enchentes e diversos deslizamentos sobre as encostas. Dia após dia, as chuvas provocaram inundações nos vales e encharcaram o solo das encostas, que deslizaram morro abaixo com consequências trágicas. Os dias que apresentaram a maior precipitação estão compreendidos entre 20 e 24 de novembro de 2008. As chuvas afetaram em torno de 60 cidades 
e mais de 1,5 milhões de pessoas, com 133 mortes, 22 desaparecidos e mais de 78.000 habitantes forçados a sair de suas casas (DIAS, 2009). Foi nesse cenário que deveriam ser feitas as intervenções com as turmas. A partir dos problemas que eram vivenciados diariamente, tentamos buscar soluções na literatura para evitar que as condições ambientais limitassem nossa prática pedagógica, entretanto, pouco se encontrou.

A Educação Física possui características próprias, bem diferentes de todas as outras disciplinas escolares, ela necessita de espaço e materiais diferenciados, os quais ainda não são parte do cotidiano da maioria das escolas brasileiras. No caso dessa Escola, as aulas possuem um espaço legítimo para sua prática, as quadras e os ginásios. Entretanto algumas características ambientais, de alguma forma, podem causar modificações nas estruturas das aulas. Os dias de chuvas são normalmente odiados pelos professores, pois se não houver um espaço coberto, disponível e exclusivo para as atividades, a situação piora.

Nesse sentido, o presente artigo é um estudo de caso da realidade escolar, vivenciada no Estágio, influenciada pelas condições ambientais. $\mathrm{O}$ objetivo desse estudo é entender como o dia de chuva se torna um desafio para a prática das aulas de Educação Física e analisar a partir do discurso dos professores investigados quais os fatores que mais contribuem para as dificuldades de atuação profissional nessa situação.

\section{Metodologia}

Inicialmente foi realizado o estágio, ou seja, a experiência da prática docente, posteriormente foi verificada que o ambiente era um problema, ao passo que as aulas não previam as condições de clima etc.. Após essa inquietação nos debruçamos no aprofundamento teórico sobre tal temática, através de buscas nas revistas Movimento, Motriz, Motrivivência, Revista da Educação Física/UEM e Pensar a Prática, consideradas revistas da linha pedagógica da Educação Física, utilizando como palavras-chave "dia de chuva" e "chuva", tendo como resultado somente 2 artigos na revista Pensar a Prática falando brevemente sobre espaço escolar e mudanças didáticas utilizadas nos dias de chuva, em decorrência de espaços não apropriados para tais condições climáticas (DAMAZIO \& SILVA, 2008; SEBASTIÃO \& FREIRE, 2009).

Devido à escassez de base teórica, foram realizadas entrevistas semi estruturadas com seis docentes universitários e seis colegas de estágio na tentativa de encontrar 
respostas a questões levantadas durante o período de docência sendo que todos já haviam sido professores escolares. As questões abaixo foram utilizadas como parâmetros nas entrevistas:

- Já teve experiência com a Educação Física Escolar (EFE)? Sistema de ensino público ou privado? Por quanto tempo?

- Quais as maiores dificuldades encontradas na prática pedagógica? O dia de chuva foi uma dificuldade?

- Quais os desafios encontrados com relação à estrutura escolar no dia de chuva? Soluções sugeridas:

- Cite aspectos/características de uma escola para solucionar os problemas encontrados:

- O dia de chuva interfere de algum modo na aplicação dos conteúdos escolares?

- Identificou mudanças comportamentais nos alunos nos dias de chuva? Quais?

- Alguma complementação?

\section{Resultados}

Todos os professores entrevistados já haviam passado por alguma instituição escolar, sendo que três trabalharam apenas em escolas públicas, um em escola pública e privada e dois em escolas privadas. Já os colegas de estágio estavam enfrentando pela primeira vez o magistério.

A maioria dos professores declarou não considerar o dia de chuva como um obstáculo, alguns inclusive sugeriram utilizar tal fenômeno natural como mais um conteúdo escolar, aproveitando-o para o desenvolvimento da corporeidade. Alguns professores citaram que encontraram dificuldades no início da carreira docente, mas com o "aumento do repertório", puderam melhorar a gama de possibilidades para utilização nos dias de chuva. A inexperiência pode justificar o fato de quase todos os estagiários citarem dificuldades nos dias de chuva, talvez pelo espaço escolar, talvez pela conjuntura escolar, talvez pela cultura escolar estabelecida.

Quanto aos desafios encontrados, tanto professores quanto estagiários, citaram a falta de espaços adequados para a prática escolar, assim como a falha na legitimação da sala de aula como um espaço para a Educação Física. Com relação à sala de aula podemos incluir como um apêndice a problemática das aulas teóricas na Educação Física, já que alguns aproveitam os dias de chuva para conversas administrativas, assuntos teóricos e metodológicos. O que é válido, mas deve ser enfatizado que não devem ocorrer improvisações. A improvisação é algo que se perce- 
be na fala de alguns entrevistados, principalmente estagiários e em observações à atuação dos professores da escola de referência.

Alguns entrevistados relataram que um quesito importante para ser um professor de Educação Física é a criatividade, sendo ainda mais importante para o dia de chuva. Porém, a criatividade não seria algo mais requintado para citar a improvisação do espaço disponível ao conteúdo de trabalho? Não é esta capacidade de improvisação, tão salientada como uma capacidade importante para o professor ante a dinamicidade da aula e do ser humano, o que transforma as aulas de Educação Física em "rola bola"? O que queremos dizer com criatividade é o "planejamento criativo" - durante a elaboração do Plano de Aula analisar as possíveis situações que podem vir a ocorrer na aula. Neste sentido os estudos de Domingues indicam uma necessidade de trabalhar a organização do trabalho pedagógico a partir do meio ambiente, entendendo que ele oferece possibilidades para planejar teórico-metodologicamente a disciplina.

As possibilidades exploratórias do meio, citadas quanto à chuva, vão desde banhos de chuva prestando atenção, corporalmente, nas gotas de chuva e suas cores à maneira como descer um morro correndo debaixo de chuva; onde podemos perceber que realmente não há limites para as relações entre este elemento da natureza e nosso corpo. Infelizmente algumas das atividades propostas não são atualmente realizáveis no espaço escolar devido, muitas vezes, ao pensamento da sociedade de que na escola, ou na maioria dos lugares, a etiqueta ou "civilidade" não incluem se molhar na chuva, rolar na grama, brincar no barro, etc., pois são atividades animalescas e nos mostram um resquício do passado não-civilizado. Em qualquer escola pode-se observar que nem todas as mães são compreensivas quando seus filhos saem sujos da escola por causa de alguma atividade nas aulas.

Infelizmente, como muitos entrevistados trouxeram à luz, e algumas pesquisas apóiam tal afirmação, a maioria das escolas públicas não está preparada para o dia de chuva, já que algumas das estruturas mais citadas pelos entrevistados não fazem parte da arquitetura escolar - salas amplas para jogos, pátio coberto livre, ginásio de esportes, etc. Tais espaços foram citados como prováveis possibilitadores de aulas menos agitadas e mais dinâmicas, possibilitando às crianças o que elas mais primitivamente querem e necessitam para o seu desenvolvimento, e que na escola, somente a Educação Física possibilita a elas 
- correr, brincar, pular, enfim, "semovimentar" (KUNZ, 2004).

Quanto a possíveis interferências no conteúdo trabalhado na EFE (Educação Física Escolar), muitos falaram que não devem ocorrer, corroborando com os ideais da Educação, já que o "conteúdo é essência", "é central, e não deve ser interferido pela mudança na dinamicidade da aula", mas observações e relatos mostram que, na prática, há interferência; devido a carências na estrutura escolar e, talvez, até experiência ou iniciativa da parte dos professores.

Como sugestão importante, alguns professores citaram a exploração desta área na formação acadêmica do professor de Educação Física, buscando uma orientação prévia, que já ocorre, sobre as adversidades encontradas como falta de material (Pedagogia do lixo), falta de estrutura física (espaços alternativos), mas ainda falta adicionar o dia de chuva como possível adversidade encontrada nas escolas.

A maioria dos entrevistados relatou notar mudanças comportamentais dos alunos nos dias de chuva, talvez pela ansiedade de sair da "jaula", talvez pela necessidade nata do "se-movimentar", talvez por outros motivos não identificados, porém a mudança é real e é relevante neste ambiente de aprendizagem.
Algo muito citado como empecilho para a Educação Física é o barulho, já que naturalmente as aulas de EF são barulhentas pelas possibilidades fornecidas aos alunos, e em dias de chuva, tudo piora, pois os espaços (saguão, sala de aula, corredor) não dão conta de amenizar tais barulhos e atrapalha outras aulas. O que fazer? Crianças brincarem quietas?

\section{Conclusões}

Não era a intenção desse trabalho encontrar receitas para o dia de chuva, nem manual de exercícios, mas sim refletir para podermos entender o que acontece na escola no dia de chuva, e com os relatos de experiências, pôde-se explicitar alguns aspectos que supúnhamos significantes para a prática pedagógica, como o espaço, tempo e sujeitos escolares. Como elementos implícitos no discurso de alguns entrevistados, o espaço escolar é elemento fundamental para uma aula de Educação Física satisfatória, algo que não acontece na maioria das escolas brasileiras.

Neste sentido Domingues (2009) afirma que os espaços esportivos contribuem com a devastação ambiental e nos ajuda a entender que há possibilidade para a prática pedagógica da Educação Física voltada para a valorização do Meio 
Ambiente. O que para nós representa a superação de conteúdos voltados apenas para o esporte para outras práticas corporais a partir do movimento, saindo de espaços destinados a práticas esportivas para ocupar outros espaços quaisquer da escola e/ou do seu entorno.

Assim, seria importante avaliar a arquitetura escolar e adaptá-la conforme o que é necessário para a realização de aulas, independente de condições externas, seja sol ou chuva. Para tanto, é importante a implantação de Políticas Públicas voltadas para o aprimoramento da Escola, que não "esqueça" da Educação Física.

Percebemos também que na formação de professores a relação entre Educação Física e Meio Ambiente poderia estar mais presente, como demonstra Domingues (2005). Ela nos ajuda a entender essa relação entre Meio Ambiente e Educação Física, quando traz a experiência de um trabalho de uma disciplina na formação de professores, desenvolvida na escola pública de uma colônia de pescadores, organizando a Educação Física a partir de dados do meio ambiente, como clima, maré, relevo entre outros e redefinindo conteúdos, em geral voltados para práticas esportivas para aulas a partir do movimento e da cultura humana.
Estamos de acordo com esses estudos também, no que diz respeito a necessidade de trabalhar elementos do meio ambiente quando se quer organizar a Educação Física Escolar, indicando a necessidade da presença de abordagens sobre Educação Física e Meio Ambiente desde a Formação de Professores.

A partir das entrevistas com os estagiários e da análise da bibliografia concluímos que é elementar uma formação acadêmica que prepare os futuros professores para enfrentar situações adversas como o dia de chuva, algo que, segundo Domingues (2005), falta no Currículo atual da maioria dos Cursos de Licenciatura em Educação Física. Para isso, propomos pensar mais no meio ambiente enquanto elemento essencial a ser tratado nas disciplinas aproximadas da Didática e Práticas de Ensino.

\section{Referências}

DAMAZIO, M.S., SILVA, M.F.P. $O$ ensino da educação física e o espaço físico em questão. Revista Pensar a prática. Goiânia, v. 11, n. 2, p.189-196, mai./ago. 2008.

DIAS, Maria Assunção F. Silva (Ed.). As chuvas de novembro de 2008 em Santa Catarina: um estudo de caso visando à 
melhoria do monitoramento e da previsão e eventos extremos. 2009. Disponível em: <www. ciram.com.br/ciram_arquivos/.../ gtc/.../NotaTecnica_SC.pdf $>$. Acesso em: 20 mar. 2010.

DIAS, Genebaldo Freire. Educação Ambiental - Princípios e Praticas. $6^{\circ}$ edição. Revisado e Ampliado pelo autor. São Paulo, Gaia, 2000.

DOMINGUES. Soraya Corrêa. Cultura Corporal e Meio Ambiente na Formação de Professores. Dissertação de Mestrado do Curso de Pósgraduação em Educação da Faculdade de Educação, UFBA, BA, 2005.

. L. Araújo, A. Ramires, M. Radicchi. Uma abordagem crítica sobre esporte e meio ambiente. Congresso Brasileiro de Ciências do Esporte, 16, Salvador, 2009. Disponível em: http://www.rbceonline.org. $\mathrm{br/congressos/index.php/}$ CONBRACE/XVI/paper/ viewFile/1038/550. Acesso em: 30 de março de 2010.

KUNZ, Elenor. Educação Física. Ensino e Mudança. $3^{a}$ ed. Ijuí: Unijuí, 2004. 208p.

SEBASTIÃO, L.L., FREIRE, E.S. A utilização de recursos materiais alternativos nas aulas de educação física: um estudo de caso. Revista Pensar a prática. Goiânia, v. 12, n. 3, p. 1-1, set./ dez. 2009.

Histórico da Escola de Educação Básica Getúlio Vargas. Disponível em: http://www. eebgetuliovargas.sed.sc.gov. br/. Acesso em: 30 de abril de 2010.

Recebido: 10/fevereiro/2010 Aprovado: 15/abril/2010. 